\title{
SAÚDE MENTAL EM TEMPOS DE SORÔCO E POSSIBILIDADES NA ATUALIDADE
}

Pontifícia Universidade Católica de Minas Gerais - PUC Minas. Mestranda. Bolsista da CAPES. Médica psiquiatra.

Pontifícia Universidade Católica de Minas Gerais - PUC Minas. Doutora. Membro da Escola Brasileira de Psicanálise (Brasil) e da Associação Mundial de Psicanálise (Paris, França). Bolsista de produtividade em pesquisa, CNPQ, nível pq2.

Maria Angélica Silva Vaccarini Ilka Franco Ferrari

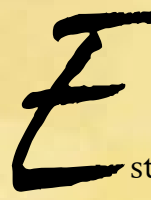

Resumo

ste texto objetiva considerar que, diferentemente do vivenciado em tempos passados, mudanças ocorrem nas práticas em Saúde Mental que possibilitam saídas para o sujeito encarcerado no mundo das drogas. Elas contam com possibilidades desse próprio sujeito e com a entrada em cena de outros atores sociais, indo além do instituído pelas políticas públicas, como a Reforma Psiquiátrica, e pelo saber profissional, surpreendendo com invenções que só acontecem quando se abre para o inusitado e se desprende do enraizamento aos mesmos paradigmas. Ilustra-o um caso clínico atendido no Centro de Atenção Psicossocial (CAPS) de Coronel Fabriciano-MG, que encontra sua própria saída seguindo os postulados usados pela equipe de saúde do Movimento dos Trabalhadores Rurais sem Terra (MST), saberes construídos em parceria inédita entre aquele movimento e a Secretaria de Estado de Saúde de Minas Gerais, através da Escola de Saúde Pública. Traçase um paralelo entre o paradigmático caso da internação manicomial da mãe e filha de Sorôco, personagens de João Guimarães Rosa, em seu livro Primeiras estórias, em que o determinismo da única e imposta saída são percebidos de forma avassaladora, tanto pelos protagonistas como pelo povo do local, comparando-se com as possibilidades contemporâneas. Diversificação das saídas permitem ampliação dos recursos, facilitando ao sujeito a localização de seu papel singular, encontrando respostas únicas, originais, abrindo outros espaços psíquicos possíveis, para além do que nos foi retratado pelo poeta. Aborda também a capacidade de interposição do saber profissional entre o sujeito e suas saídas, por estarem estas fora do instituído como saber legítimo.

Palavras-chave: Guimarães Rosa. Drogadição. Reforma Psiquiátrica. Soluções singulares. 


\section{alemens \\ ESPUC \\ BELO HORIZONTE - N. 28 - 2016}

\section{Introdução}

No conto "Sorôco, sua mãe, sua filha", João Guimarães Rosa (2001) apresenta-nos uma família que caminha pelos interiores das Minas Gerais, em direção a uma estação de trem, onde um vagão especial, com grades na janela à semelhança de cadeias, espera por dois de seus membros: a mãe e a filha de Sorôco. Ambas acometidas pela loucura, de uma forma que ele não mais poderia suportar, apesar de toda a sua resistência. O destino do trem é conhecido por todos do lugar: Barbacena, ou seja, para um dos manicômios situados naquela cidade. O governo mandou o vagão. Não há outra saída (ROSA, 2001).

A dor do momento é dividida entre os moradores do lugar, como um acontecimento. Em silêncio. Até que a filha o quebra com uma canção. Sem pé nem cabeça, sem tom, com palavras desemendadas, como a loucura lhe permite. Mas uma canção. Tempo depois a mãe de Sorôco a olha nos olhos e passa a acompanhá-la, cantando junto, mas à sua forma. Também louca. As duas são enviadas para aquele destino, de onde não mais voltarão. Nunca mais.

A dor dessa atitude de despachar seus únicos familiares, embora loucas, faz Sorôco "perder o de si, parar de ser" (ROSA, 2001, p. 66). O que só o leva a uma saída, qual seja cantar "a cantiga mesma, de desatino" (ROSA, 2001, p. 66).

É nítido o determinismo imposto na época como solução para a loucura tornada insuportável. Internação em manicômios, para a vida toda. $\mathrm{O}$ trem, a estrada, o destino traçado, a ida sem mais volta. O lugar previamente definido, não escolhido, não discutido. Apenas cumprido, apesar da dor. Dor calada, dor-silêncio, no máximo transformada em dor-canção. Dor que chega como a única ajuda que o governo sabe dar: um vagão com janelas gradeadas cuja estrada só tem ida.

Longos anos se passaram, vários pacientes e familiares receberam o mesmo destino durante esse tempo, ainda que não poeticamente descrito, como o da mãe e da filha de Sorôco. Afinal, Barbacena sempre funcionou com lotação esgotada, ou mais que isto, com os denominados "leitos-chão", aqueles que existem além de toda a capacidade que uma instituição hospitalar possa hospedar pessoas. Mas aí estaríamos falando de hospitais e de pessoas. 


\section{alemens \\ ESPUC \\ BELO HORIZONTE - N. 28 - 2016}

\section{Fora da ficção}

Em 2001, sancionada a lei Paulo Delgado, implanta-se a Reforma Psiquiátrica no Brasil, resultado da luta da sociedade civil, então representada pelos usuários, familiares e trabalhadores da saúde mental, pois até então nosso país funcionava com estruturação e lógica manicomiais. Com a Reforma, começam a ser aventadas respostas diferenciadas, não padronizadas, para a loucura. A possibilidade do tratamento dos portadores de sofrimento mental grave em seu próprio território deixa aquele "vagão especial com grades" na inutilidade histórica. Os manicômios vão sendo desativados, transformados, substituídos por dispositivos diversos, como os CAPS, os Centros de Convivência, as Residências Terapêuticas.

Em um desses dispositivos, o CAPS-2 de Coronel FabricianoMG, atendo ao paciente B., de 22 anos de idade, trazido pelo pai (Sorôco?), após informações da comunidade de que ele estava sendo acorrentado ao pé da mesa, em sua casa. A história é de drogadição por crack e maconha, já com as desdobradas consequências que a situação pode ofertar, como venda de artigos da casa para a compra de drogas, idas do pai ao morro para pagar dívidas, crises de fissura, ansiedade, agressividades, ameaças de morte. A primeira demanda que surge, para o caso, vem da comunidade incomodada com a questão do aprisionamento de $\mathrm{B}$, pelo pai. As demais demandas repetem o mesmo colorido que tal problema insere nas famílias que o enfrentam, respeitando-se suas variações subjetivas, quais sejam cansaço em lidar com a situação, desentendimento entre diversos membros da família, divergência de posturas, transparência de conflitos anteriormente presentes no grupo familiar. Mas o acorrentamento... este soa diferente, destoa. Desafina como a canção das loucas, filha e mãe de Sorôco.

Acontece que este pedido, aparentemente dissonante, soa bem entoado com a "canção" do próprio B., pois, através dele, soubemos que esta é sua forma, talvez desafinada, porém singular, de lidar com sua dor: ele mesmo pede, implora ao pai que o acorrente, como uma forma de proteger-se de sua necessidade da droga, quando esta o invade de forma avassaladora. Atado ao pé da mesa, acorrentado a um objeto que é móvel, que pode se deslocar, ou com a corrente ao redor de suas pernas trancada com cadeado, quando necessita caminhar, como quando vai ao CAPS, realiza uma forma aparentemente precária de se imobilizar e consegue alguma forma de contenção 
de seus próprios desatinos. Tenta, à sua maneira, modificar seu destino.

A equipe o recebe, mas o que haveria neste caso a fazer? Qual seria a possível ajuda que o governo poderia enviar, agora sem contar com aquele antigo vagão com grades nas janelas?

Medidas do século XXI são providenciadas. Medicamentos para reduzir a ansiedade, a compulsão e a depressão. Um pouco da tensão é reduzida, B. já consegue diminuir seus pedidos de acorrentamento. Mas eles ainda ocorrem. Algumas vezes não consegue lançar mão de sua própria saída, não consegue pedir a contenção e se entrega ao uso das drogas.

B. não aceitou manter a permanência-dia, oficinas ou outros recursos institucionais. No entanto, frequentava semanalmente a psicoterapia, vinha de dois em dois meses às consultas psiquiátricas, mantinha o uso de seus medicamentos, às vezes usava drogas, em outras se acorrentava através do pai.

\section{Uma saída singular}

Faço um corte neste ponto para relatar uma experiência pessoal vivida recentemente. Tive a oportunidade de entrar em contato com uma publicação da Escola de Saúde Pública do Estado de Minas Gerais (ESP-MG), que foi solicitada pela Secretaria de Estado de Saúde para construir uma parceria inédita com o setor de saúde do MST. A publicação é o registro dessa experiência, cuja ação se concretizou na Oficina de Educação Popular em Saúde Mental para Populações Assentadas e Acampadas em Projetos de Reforma Agrária em Minas Gerais, desenvolvida no período de novembro de 2012 a dezembro de 2013 (MINAS GERAIS, 2014). O objetivo dessa Oficina foi estabelecer diálogos entre os trabalhadores do SUS e os militantes do MST, que possibilitassem a construção de novos saberes e práticas em torno do sofrimento mental grave, do uso prejudicial de álcool e outras drogas e do direito à saúde.

Como é citado no "Caderno", os trabalhadores do Movimento utilizam-se de práticas ditas alternativas, como o uso de ervas medicinais, bioenergética, florais, geoterapia. Os técnicos da ESP-MG articularam com os participantes do Movimento um saber singular, respeitando as práticas já apropriadas pelos trabalhadores em seu cotidiano, tecendo uma forma de lidar com o adoecimento mental, incluindo o abuso de drogas, dentro da lógica da redução de danos. A publicação descreve os 


\section{alemens \\ ESPUC \\ BELO HORIZONTE - N. 28 - 2016}

aspectos do desenvolvimento desse genuíno trabalho.

Como esses fatos se entrelaçam com o atendimento clínico de B. e com a estória de Sorôco?

B. retorna para mais um de seus atendimentos no CAPS. Desta vez, não vem acompanhado do pai. Uma irmã jovem e casada o traz e apresenta-se como moradora de um acampamento do MST, na época instalado nas imediações de nosso município. Diz de seu desejo de levar B. consigo, para morar com seu núcleo familiar no acampamento, onde pretende oferecer tratamento ao irmão, ajudá-lo em sua dificuldade de fazer frente ao uso das drogas, das quais ele sempre diz querer se livrar.

Articulamos, assim, como seriam administrados os medicamentos, sua manutenção, arranjos que pudessem garantir o que tinha sido conseguido até então, mesmo que de forma precária.

B. vai com sua irmã, rumo a um contexto social que desconheço, mas com o qual tive um breve e parcial contato através da publicação citada. Trata-se de um contexto totalmente fora do meu cotidiano de trabalho e de meus referenciais teóricos.

Trinta dias depois, o pai comparece sozinho ao CAPS para buscar nova receita dos medicamentos. Nova prescrição é feita, mas oriento que não poderemos manter medicamentos à distância, sem a presença de $\mathrm{B}$. nas consultas. Agendamos encontro presencial para sessenta dias depois. Desta vez, B. vem acompanhado pelo marido de sua irmã. Está irreconhecível. Vestido com muito zelo e vaidade, muito bem higienizado, sem suas olheiras de costume e mostrando estado geral saudável, pele bem hidratada e corada, enfim, um jovem bonito e bem apresentado. Conversa com tranquilidade, diz estar bem, entrosado com os moradores do acampamento, tem vida social. Falamos sobre as novas possibilidades afetivas na sua comunidade. Sorri, interage, não mostra mais aquela ansiedade constante, aquele olhar furtivo de quando pedia ajuda para conseguir manter-se sem usar drogas.

Durante a consulta relata que fez aqueles tratamentos alternativos: com argila, ervas e outras práticas. Certamente foi também acolhido, inserido no grupo. Assim, ele mesmo conseguiu suspender gradualmente o uso da medicação e fazia aproximadamente três meses que não a utilizava. Diante desse quadro, digo-lhe que, no momento, estava liberado do acompanhamento psiquiátrico. Ele se vai com o cunhado, 
depois de despedir-se de outros técnicos da equipe do CAPS. Sabe para onde vai e escolhe seguir em frente, disposto a protagonizar sua própria história.

Não sei ao certo sobre todos os cuidados que recebe do grupo ao qual aderiu, mas com certeza estão sendo oferecidos recursos com os quais vem conseguindo alguma possibilidade de reinventar-se. Não precisa mais das correntes atreladas ao pé da mesa, na verdade correntes simbólicas, pedido de socorro ao pai. Talvez esteja descobrindo a importância dos laços e a não necessidade dos nós.

Desconheço qual será a viagem de B. ao longo da trajetória de sua vida. Afinal, no dizer de nosso Guimarães Rosa, "mire veja: o mais importante e bonito, do mundo, é isto: que as pessoas não estão sempre iguais, ainda não foram terminadas - mas que elas vão sempre mudando" (ROSA, 2006, p. 23), ensinamento literário comprovável na clínica. A mim, no entanto, não preocupa se as drogas estarão ou não definitivamente fora de seu caminho, mas encanta-me saber que ele descobriu possibilidades de escolher em qual vagão quer entrar para seguir seu percurso na vida, diferentemente do aprisionamento anterior pelas drogas ou por correntes de ferro. Estas não precisam ser mais o seu destino.

Algumas perguntas, porém, insistem em conviver com meus dias de trabalho. Qual seria minha postura, enquanto trabalhadora de saúde mental da rede pública, caso não tivesse acontecido aquele meu encontro com o trabalho da ESP-MG e do MST? Estaria, como representante do "governo", enviando um novo vagão com grades a B., na forma de preconceito em aceitar práticas diferentes das que preconizo? Estaria funcionando como um obstáculo para que ele encontrasse suas próprias saídas, fizesse suas próprias invenções? Haveria o risco de que eu considerasse o saber com o qual trabalho como verdade, impedindo, ou dificultando o caminho escolhido por B.? Meu trabalho poderia perpetuar sua saída única, que era a de solicitar correntes?

A algumas perguntas eu consigo responder, para outras aceito contribuição, de modo a refletir permanentemente sobre minha prática.

Vale ressaltar que, com a Reforma Psiquiátrica, não há mais o determinismo de épocas passadas, tão sofrido, como o exemplificado com Sorôco. Porém, mesmo com a construção de novos dispositivos, novas práticas, novas possibilidades, não 
esgotamos, todavia, as variantes e novíssimas possibilidades de o sujeito encontrar seus caminhos. A existência de serviços substitutivos não garante, por si só, a qualidade e a eficiência do atendimento aos portadores de sofrimento mental grave. Os processos de adoecimento, assim como os sujeitos que os abarcam, escapolem aos enquadramentos institucionais, fazendo negociações diversas, múltiplas, criativas, com outros dispositivos sociais que não estão, nem deveriam necessariamente estar, inseridos na rede de serviços ofertados pelo Estado. Outros laços, fora do discurso assistencialista, podem e devem ser buscados, para que as respostas congeladas não se reproduzam, sendo necessária a utilização de todas as possibilidades presentes em um território, ou mesmo fora dele.

Como profissionais de saúde mental, entre os quais me situo, é premente que estejamos alertas às armadilhas do nosso saber, que pode nos exigir uma postura hegemônica sobre outros, que divergem daquele em que militamos. Mantermos nossa postura flexibilizada frente ao conhecimento, que, assim como os sujeitos, nunca é estanque, possibilita que nos deparemos com a criatividade de quem encontra novas estratégias para seu percurso, numa verdadeira lição de intersetorialidade. Atentos ao ensinamento com que nos brindou Rosa: "eu quase que nada não sei. Mas desconfio de muita coisa" (ROSA, 2006, p. 15), é necessário que escutemos diversas canções, respeitando a singularidade da escolha do sujeito que as quer cantar, pois viver, "viver é etcétera" (ROSA, 2006, p. 94).

\section{MENTAL HEALTH IN TIMES OF SORÔCO AND CURRENT POSSIBILITIES}

ABSTRACT

Unlike what was experienced in the past, mental health practices are changing, which enables us to find different outputs for drug addicts. These outputs can now count on the possibilities of the subject himself in addition to the participation of other social actors, going beyond what was established by public policies, like the Psychiatric Reform, and professional knowledge, surprising with solutions that can only happen when we 
get rid of deep-rooted paradigms. As an example, this article presents a case treated in Centro de Atenção Social (CAPS), in the city of Coronel Fabriciano, Brazil, which found its own output according to the postulates used by the health team of Movimento dos Trabalhadores Rurais Sem Terra (MST), building an unprecedented partnership between this movement and Secretaria de Estado de Saúde de Minas Gerais, through Escola de Saúde Pública. This study draws a parallel between the paradigmatic case of asylum admission of the mother and daughter of Sorôco, characters of João Guimarães Rosa's book Primeiras Estorias, when the determinism of the only and forced output is overwhelmingly noted by both protagonists as by the local people, comparing to contemporary possibilities. Diversifying outputs allows the expansion of the resources, making easier for the subject to locate its singular role and find out unique and original answers, opening other possible psychic spaces beyond the one portrayed by the poet. We also discuss the ability of interposing professional knowledge between the subject and his outputs, by the fact that these are outside the borders of what was instituted as legitimate knowledge.

Keywords: Guimarães Rosa. Drug addiction. Psychiatric Reform. Exceptional solutions.

\section{REFERÊNCIAS}

MINAS GERAIS. Cuidados em saúde mental: diálogos entre o MST e o SUS. Belo Horizonte: ESP-MG, 2014.

MINAS GERAIS. Secretaria de Estado de Saúde. Atenção em saúde mental. Organização de Marta Elizabeth de Souza. 2.ed. Belo Horizonte: SES, 2007

ROSA, João Guimarães. Grandes sertão: veredas. Rio de Janeiro: Nova Fronteira, 2006

ROSA, João Guimarães. Sorôco, sua mãe, sua filha. In: ROSA, João Guimarães. Primeiras estórias. Rio de Janeiro: Nova Fronteira, 2001.

Recebido em: 10/07/2015

Aceito em: 11/11/2015 